This item was submitted to Loughborough's Research Repository by the author.

Items in Figshare are protected by copyright, with all rights reserved, unless otherwise indicated.

\title{
3D printed dielectric Fresnel lens
}

PLEASE CITE THE PUBLISHED VERSION

http://dx.doi.org/10.1109/EuCAP.2016.7481775

PUBLISHER

IEEE

VERSION

AM (Accepted Manuscript)

LICENCE

CC BY-NC-ND 4.0

REPOSITORY RECORD

Zhang, Shiyu. 2019. "3D Printed Dielectric Fresnel Lens”. figshare. https://hdl.handle.net/2134/23067. 


\title{
3D Printed Dielectric Fresnel Lens
}

\author{
Shiyu Zhang \\ School of Electronic, Electrical and Systems Engineering, Loughborough University, Loughborough, UK, LE11 3TU. \\ S.Zhang@lboro.ac.uk
}

\begin{abstract}
This paper presents the design and fabrication of a zone plate Fresnel lens. 3D Printing is used for rapid prototyping this low-cost and light-weight lens to operate at 10 GHz. This lens is comprised of four different 3D printed dielectric zones to form phase compensation in a Fresnel lens. The dielectric zones are fabricated with different infill percentage to create tailored dielectric constants. The dielectric lens offers $18 \mathrm{dBi}$ directivity at $10 \mathrm{GHz}$ when illuminated by a waveguide source.
\end{abstract}

Index Terms - Fresnel lens, zone plate, flat lens, additive manufacturing, 3D Printing

\section{INTRODUCTION}

Lens antennas have been widely studied due to the highly directional radiation, wide angle scanning and formed beam. The lenses are able to transform the spherical wave fronts into plane wave fronts to enhance the directivity of the antennas [1]-[5]. Fresnel lenses (FL) are relatively thin and flat, they usually have smaller volumes and weighs compared with conventional shaped lenses. They can be fabricated by using inexpensive dielectric materials, which makes them suitable for consumer applications [6]-[9].

The traditional fabrication approaches for dielectric lenses are dominated by using mechanical machining. The lens surface can be grooved to lead the wave have higher phase velocity by travelling through the grooved zones. Another method to accomplish the phase correction is to divide the lens into several concentric zones with different dielectric constants. This approach can be either realised by several tightly fitted concentric dielectric rings with various dielectric constants, or using uniform dielectric material that is perforated to create different dielectric zones [10], [11]. The FL that fabricated using the dielectric zones method generally has uniform thickness with flat surface, however the precisely machining is involved in which increases manufacturing complexity. Moreover, the machining technique removes or shapes parts of the raw materials which generates material waste.

The three-dimensional (3D) Printing technology constructs objects as successive layers. It is one-step process and able to generate complex internal structures. It significantly simplifies the manufacture process and reduces material waste. Furthermore, 3D Printing can create perforated structures that are difficult to be realised by machining due to the mechanical strength of material.
The dielectric materials can be custom-made by using 3D Printing [12]. By adjusting the infill percentage of the 3D material, it can create materials with bespoke structures with customised dielectric constant values. The 3D Printed dielectric materials which are cost efficient and can be rapidly prototyped. This gives engineers more freedom in antenna design.

This paper presents a novel dielectric FL that fabricated by using 3D Printing. In this work, an ABS based 3D Printing filament PREPERM ${ }^{\circledR}$ TP20280 was used. The dielectric constant of this 3D filament was characterised as 4.4 and loss tangent was 0.004 . This material could be both injection moulded or extruded to form a designed shape. A fused deposition modelling (FDM) Makerbot ${ }^{\circledR}$ Replicator ${ }^{\mathrm{TM}} 2 \mathrm{X}$ 3Dprinter was used to fabricate the FL. The extrusion temperature was $230^{\circ} \mathrm{C}$ with the $110^{\circ} \mathrm{C}$ heated platform. The lens geometry was designed with radially varied infill percentages. Then the dielectrics were printed as non-solid which leads air voids into the lens and therefore the dielectric constants of the zones in the FL were tailor-fabricated. The entire FL was fabricated in one-step process.

\section{PROTOTYPE DESIGN}

The design of the FL was carried out at $10 \mathrm{GHz}$ and the lens had a uniform thickness. The radii ( $R i)$ for each dielectric zone can be determined using:

$$
R_{i}=\sqrt{2 i F\left(\frac{\lambda_{o}}{P}\right)+\left(i \frac{\lambda_{o}}{P}\right)^{2}} \quad i=2,3, \ldots, P
$$

Where $P$ is the phase correcting index, $\lambda_{o}$ is the design wavelength and $F$ is focal length. In this work the lens was designed for quarter wave phase correction. An $F / D=0.3$ was chosen, to obtain a short focal length. The diagram of the FL is shown in Fig. 1. The focal length $F$ was $30 \mathrm{~mm}$.

The thickness of the lens $t$ is related to the dielectric constants of two adjacent Fresnel zones and it can be obtained using:

$$
t=\frac{\lambda_{o}}{P\left(\sqrt{\varepsilon_{s}}-\sqrt{\varepsilon_{s-1}}\right)} \quad s=2,3, \ldots, P
$$




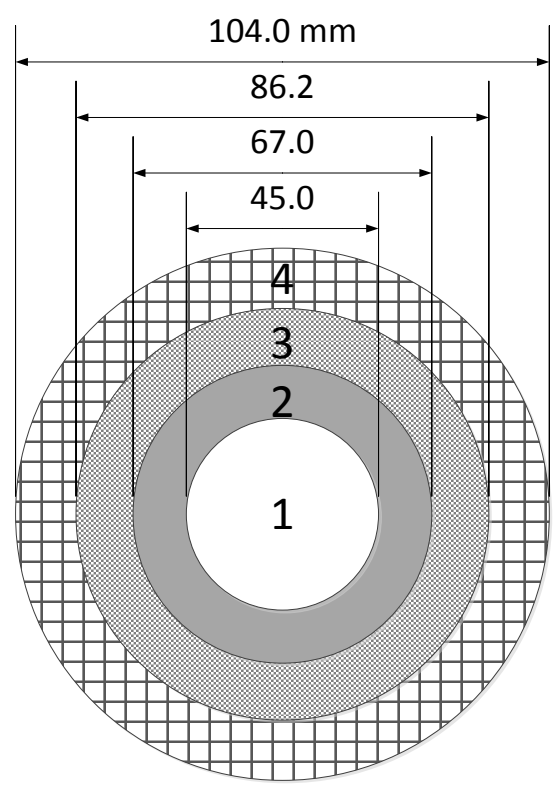

Fig. 1. Dielectric Fresnel lens design

In this design, the highest dielectric constant value was 4.4 which was realised by using $100 \%$ infill 3D material. In order to reduce the thickness and the weight, the centre ring with the minimum dielectric constant was equal to 1 which was air. Therefore the lens was made of three dielectric rings and one air ring per full-wave zone. By substituting $P=4$, $t=20.5 \mathrm{~mm}, \varepsilon_{\max }=4.4, \varepsilon_{\min }=1$ and $\lambda_{o}=30 \mathrm{~mm}$ into (2), the dielectric constant value for each ring could be obtained. The values with the corresponding infill percentages for the Fresnel zone radii are given in Table I.

TABLE I FRESNEL ZONE RADII AND CORRESPOIND DIELECTRIC CONSTANTS

\begin{tabular}{|c|c|c|c|}
\hline $\boldsymbol{i}$ & $\boldsymbol{\varepsilon}_{\boldsymbol{r}}$ & $\boldsymbol{R}_{\boldsymbol{i}}$ in $\mathbf{~ m m}$ & Infill percentage in $\mathbf{~}$ \\
\hline 1 & 1.0 & 22.5 & 0 \\
\hline 2 & 4.4 & 33.5 & 100 \\
\hline 3 & 3.0 & 43.1 & 58.8 \\
\hline 4 & 1.9 & 52.0 & 25.6 \\
\hline
\end{tabular}

\section{RESULTS}

A simulation was carried out using CST MICROWAVE STUDIO. The 3D modelling of this dielectric FL is shown in Fig. 2. The innermost ring was empty which had equivalent dielectric constant $=1$. The empty centre significantly reduced the weight of the lens. A rectangular waveguide source with dimension of $22.86 \mathrm{~mm} \times 10.16 \mathrm{~mm}$ was located at the focal point on the lens axis.

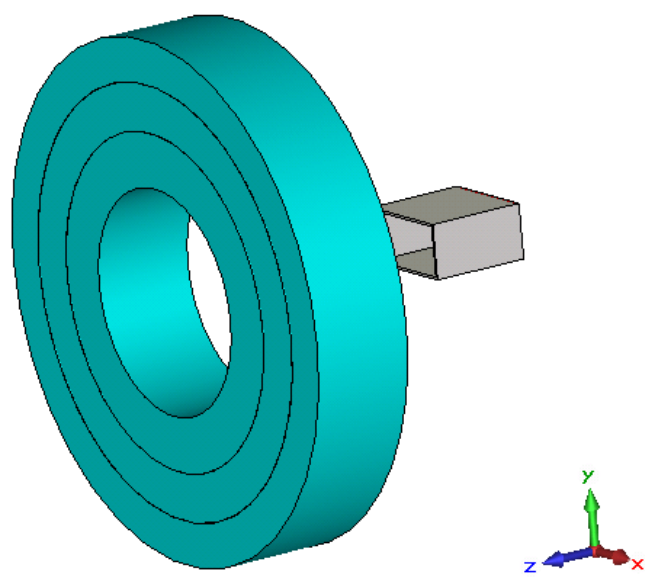

Fig. 2. The dielectric FL is illuminated by a rectangular waveguide source located on the axis

The simulated electric field in the $X o Z$ plane of the dielectric FL with the waveguide source is shown in Fig. 3. It shows that FL reduced the width of the main radiation lobe of the source, which would enhance the directivity and led to an increased gain. The far field patterns of the dielectric FL at the frequency $10 \mathrm{GHz}$ is shown in Fig. 4. This dielectric FL antenna had directivity $18.2 \mathrm{dBi}$. The directivity was significantly increased at boresight (theta $=0^{\circ}$ ). The $-3 \mathrm{~dB}$ angular width was approximately $16^{\circ}$. Since this dielectric FL had a small focal length, the short distance between FL and waveguide reduced the side lobe level.

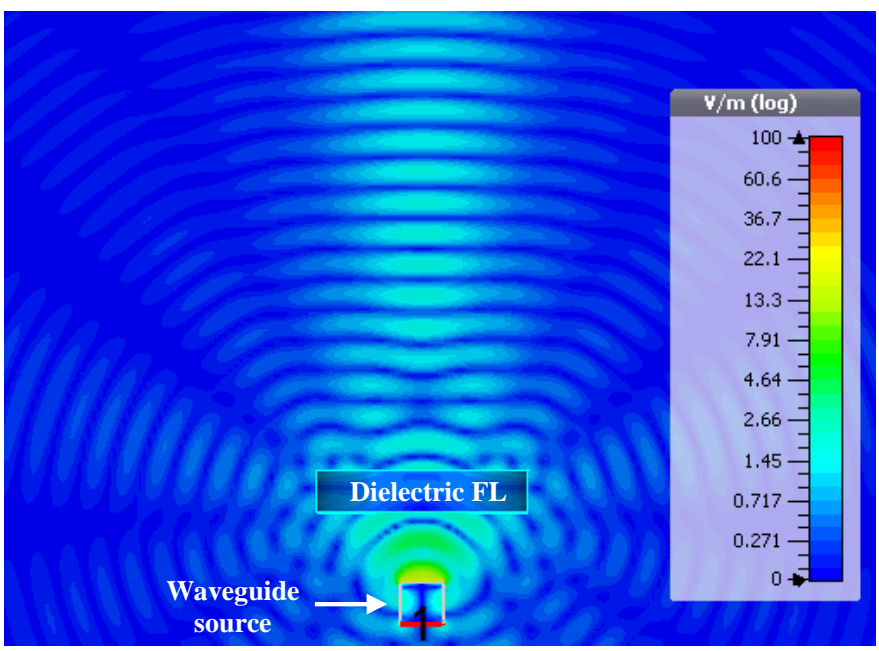

Fig. 3 Simulated electric field in XoZ plane of the dielectric FL with the waveguide source at $10 \mathrm{GHz}$ 


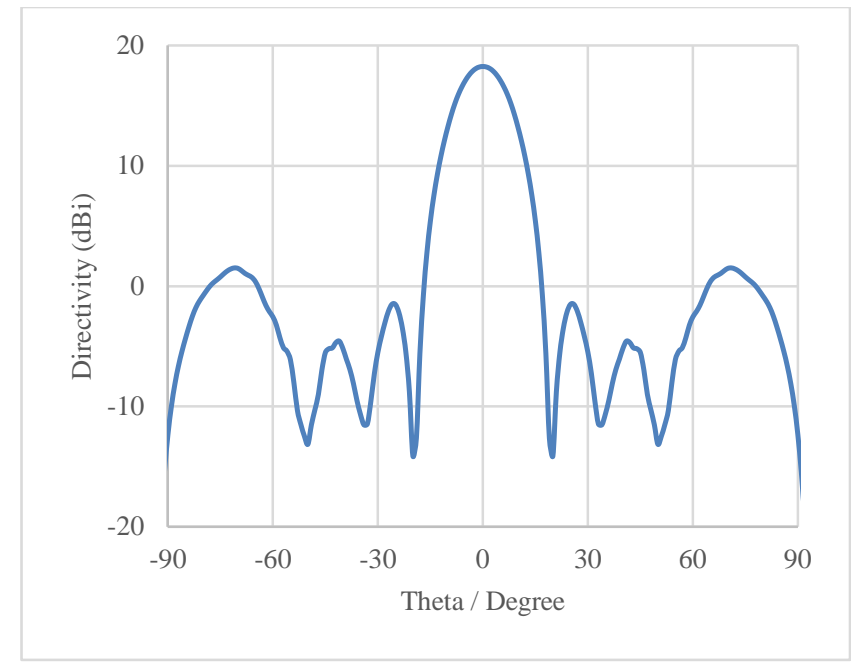

Fig. 4. Simulated Far field pattern of dielectric FL in $\mathrm{XoZ}$ plane at $10 \mathrm{GHz}$

\section{CONCLUSION}

This paper has presented a low-profile and light-weight dielectric Fresnel lens. The $10 \mathrm{~cm}$ diameter prototype lens with $90^{\circ}$ phase correction was comprised of three dielectric rings and one empty ring at the centre. The dielectric FL antenna offered directivity enhancement and suitable for various antenna applications.

The rapid prototyping 3D Printing technique was used for fabrication this dielectric lens to give bespoke dielectric constants for each ring. The dielectric rings were printed as non-solid internal structures with specific material infill percentage. The entire lens could be $3 \mathrm{D}$ printed in a singlestep process without machining or assembling, which significantly simplified the manufacturing process.

\section{ACKNOWLEDGMENT}

The authors would like to thank the Premix for providing the 3D Printing filament.

\section{REFERENCES}

[1] D. M. Pozar, "Flat lens antenna concept using aperture coupled microstrip patches,” Electronics Letters, vol. 32, no. 23, p. 2109, 1996.

[2] R. Yang, W. Tang, and Y. Hao, "A broadband zone plate lens from transformation optics.," Optics express, vol. 19, no. 13, pp. 1234812355, 2011.

[3] Y. Zhang, R. Mittra, and W. Hong, "On the Synthesis of a Flat Lens using a Wideband Low-Reflection Gradient-Index Metamaterial," Journal of Electromagnetic Waves and Applications, vol. 25, no. 16, pp. 2178-2187, 2011.

[4] H. F. Ma, B. G. Cai, T. X. Zhang, Y. Yang, W. X. Jiang, and T. J. Cui, "Three-dimensional gradient-index materials and their applications in microwave lens antennas," IEEE Transactions on Antennas and Propagation, vol. 61, no. 5, pp. 2561-2569, 2013.

[5] A. D. Olver and B. Philips, "Integrated lens with dielectric horn antenna," Electronics Letters, vol. 29, no. 13, p. 1150, 1993.

[6] D. N. Black and J. C. Wiltse, "Millimeter-Wave Characteristics of Phase-Correcting Fresnel Zone Plates," Microwave Theory and
Techniques, IEEE Transactions on, vol. 35, no. 12, pp. 1122-1129, 1987.

[7] H. Hristov and M. Herben, "Millimeter-wave Fresnel-zone plate lens and antenna," IEEE Transactions on Microwave Theory and Techniques, vol. 43, no. 12, pp. 2779-2785, 1995.

[8] H. D. Hristov and J. M. Rodriguez, "Design Equation for Multidielectric Fresnel Zone Plate Lens,” IEEE Microwave and Wireless Components Letters, vol. 22, no. 11, pp. 574-576, Nov. 2012.

[9] L. P. Kamburov, J. M. Rodriguez, J. R. Urumov, and H. D. Hristov, "Millimeter-Wave Conical Fresnel Zone Lens of Flat Dielectric Rings," IEEE Transactions on Antennas and Propagation, vol. 62, no. 4, pp. 2140-2148, 2014.

[10] A. Petosa and A. Ittipiboon, "Design and performance of a perforated dielectric Fresnel lens,” IEE Proceedings - Microwaves, Antennas and Propagation, vol. 150, no. 5, p. 309, 2003.

[11] S. Petosa, A.; Ittipiboon, A.; Thirakoune, "Investigation on arrays of perforated dielectric fresnel lenses," Microwaves, Antennas and Propagation, IEE Proceedings, vol. 153, no. 3, pp. 270 - 276, 2006.

[12] S. Zhang, C. C. Njoku, W. G. Whittow, and J. C. Vardaxoglou, "Novel 3D printed synthetic dielectric substrates," Microwave and Optical Technology Letters, vol. 57, no. 10, pp. 2344-2346, Oct. 2015. 